\title{
Cuidar no lugar: um apelo ao sentido de coerência e à resiliência
}

Paula Broeiro*

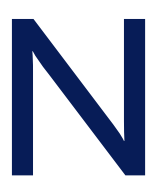

o contexto do envelhecimento populacional e do crescimento do número de idosos com doenças crónicas debilitantes, a necessidade de cuidados não médicos (cuidar) e o papel de quem cuida (cuidador informal) emergem como uma questão política, sociológica e económica essencial. ${ }^{1}$ A evidência internacional mostra que a maioria das pessoas preferiria ser cuidada e morrer em casa, se lhe fosse permitido escolher, sendo as pessoas com 75 e mais anos as que mais desejam morrer em casa $(66,2 \%) .^{2}$ A congruência ou concordância entre o lugar de preferência e o real de morte pode vir a ser um indicador de qualidade dos cuidados de saúde. ${ }^{3}$

Alguns países têm reagido às alterações sociodemográficas mais recentes implementando, com sucesso, políticas de envelhecimento no lugar. ${ }^{4}$ Envelhecimento no lugar tende a concentrar-se na prestação de serviços e apoio às pessoas mais idosas para que se mantenham nas suas casas. ${ }^{4} \mathrm{~A}$ abordagem implícita em envelhecimento no lugaré complexa pela diversidade das intervenções necessárias ou em falta (e.g., habitação e custo; local de residência; disponibilidade e acessibilidade de serviços de cuidados e apoio; ambiente físico; recursos de saúde) e variabilidades antropológica e sociocultural das diferentes comunidades onde os idosos se inserem..$^{5} \mathrm{O}$ envelhecimento no lugar não é uma escolha simples e pode mesmo não ser a melhor solução para as pessoas mais idosas e suas famílias. ${ }^{6}$

No Canadá e nos Estados Unidos, os cuidadores familiares poupam, aos seus sistemas de saúde, cerca 25 mil milhões e 350 bilhões de dólares, respetivamente. ${ }^{7}$ Quando bem suportados na comunidade (e.g., recursos informativos, emocionais e instrumentais), os cuidadores familiares conseguem enfrentar e ultrapassar dificuldades e, consequentemente, prestar cuidados de

*Directora da Revista Portuguesa de Medicina Geral e Familiar superior qualidade, com melhor recuperação funcional. Por outro lado, quando lhes faltam apoios e recursos, elevam-se os custos financeiros, físicos e psicossociais, pondo em causa a qualidade dos seus cuidados. ${ }^{\text {? }}$

A experiência de cuidar por ser tida como uma obrigação familiar ou filial, que coloca uma forte ênfase no papel da família e nos deveres e obrigações que são esperados cumprir, requer ainda a consideração cultural. ${ }^{7}$ Outro fator que interfere na capacidade adaptativa da família é a história natural da doença (e a compreensão e significado que as famílias lhe atribuem) (e.g., acidente vascular cerebral - AVC, cancro avançado) que tem implicações na capacidade dos familiares se prepararem para a transição para um novo papel de cuidadores. ${ }^{7}$ As diferenças adaptativas das famílias decorrem da natureza e evolução de cada evento crítico; no AVC, o aparecimento súbito e posterior cronicidade da dependência difere do cancro avançado que, em geral, tem um início mais ou menos insidioso e um final com stressores de intensidade dependente do controlo sintomático.

As mudanças colocam exigências aos cuidadores - a estrutura de apoio informal -, os quais são muitas vezes responsáveis por fornecer suporte físico e emocional, em geral, a pessoa que passa mais tempo com o doente, sendo a experiência de cuidar um fenómeno complexo, com impacto em todos os aspetos da vida e, por vezes, paradoxal: elevada satisfação, sensação de realização e satisfação emocional, a par de tensão emocional e do risco de adoecer. ${ }^{1,8}$

A literatura tem-se centrado na sobrecarga dos cuidadores, que é utilizada como indicador da experiência de cuidar. Todavia, existe muita discordância sobre o que o termo comporta e como deve ser utilizado, bem como na coerência e rigor da definição. ${ }^{7}$ A dificuldade em concetualizar ou definir sobrecarga do cuidador ocorre porque o conceito é complexo, abrangendo as 
tensões físicas, psicológicas, emocionais, sociais e financeiras, a par da difícil distinção entre "subjetivo" e "objetivo" da carga. ${ }^{7}$ Contudo, sendo o cuidador o elemento crítico do cuidado no lugar, se a carga se torna demasiada, o cuidado pode ser seriamente comprometido e levar à institucionalização do doente. ${ }^{1,7}$

O que se passa em Portugal? Em Portugal, a Rede Nacional de Cuidados Continuados (RNCCI), criada em 2006, veio dar resposta às necessidades sociais e de saúde decorrentes do envelhecimento populacional. ${ }^{10}$ Consiste numa estrutura de articulação intersetorial que, embora disponha de uma coordenação nacional, se caracteriza pela descentralização ao nível das regiões de saúde e pela cobertura nacional. ${ }^{10} \mathrm{~A}$ prestação de cuidados de saúde e de apoio social é assegurada por diferentes tipologias de cuidados em que as Equipas de Cuidados Continuados Integrados (ECCI), que emergem das Unidades de Cuidados na Comunidade (UCC), têm um papel preponderante na manutenção dos doentes na comunidade. Direcionam a sua intervenção multidisciplinar a pessoas em situação de dependência funcional, doença terminal ou em processo de convalescença, sempre que exista um cuidador. ${ }^{10}$

Por razões profissionais tenho acompanhado diferentes ECCI e observado a experiência de cuidar, numa viagem pessoalmente enriquecedora. $O$ sucesso do cuidar no lugar parece ser uma experiência individual que nem sempre depende de fatores reprodutíveis, como a escolaridade, os recursos ou o suporte ao cuidar. Observei cuidadores em situação de pobreza extrema (habitação e rendimento), efetivos no cuidar e sem sobrecarga, reconhecendo neles a gratuitidade do cuidar no lugar. Pude constatar a capacidade de prestar cuidados tecnológicos (e.g., administração de injetáveis, determinação de glicemia capilar) por cuidadores com baixo nível de escolaridade ou mesmo analfabetos, a par de cuidadores socialmente evoluídos que, cuidando de doentes pouco dependentes, sentiam elevada sobrecarga e incapacidade. Estes exemplos levam-me a confirmar que o sucesso do cuidar depende de diversos fatores: sociais, culturais, relacionais (e.g., prévios à dependência), expectativas de vida, características equivalentes ao sentido de coerência (que nos conduz à mudança de comportamentos) e resiliência (que ajuda a ultrapassar adversidades).

Esta reflexão, já realizada por outros, levou à reali- zação de estudos que avaliaram o sentido de coerência (SOC) entre cuidadores de pessoas com demência e que revelaram que cuidadores com baixa sobrecarga apresentaram score de SOC significativamente superior àqueles com elevada sobrecarga, ${ }^{11}$ prevendo-se que intervenções que melhorem SOC [A escala de SOC avalia três dimensões: capacidade de a pessoa entender o que aconteceu (cognitiva); capacidade de controlar a situação por conta própria ou através de recursos sociais (instrumental/comportamental); e capacidade de encontrar significado (motivacional)] possam ser eficazes na prevenção da sobrecarga do cuidador de doentes com demência. ${ }^{11-12}$

O conceito de resiliência permite compreender por que, face a uma situação adversa semelhante, umas pessoas se saem melhor do que outras. O modelo socioecológico de resiliência reconhece que os fatores sociais e ambientais são tão importantes como a personalidade individual. Os princípios que ajudam a explicar um modelo socioecológico de resiliência incluem: a equifinalidade (bons meios para bons fins), impacto diferencial (processo de proteção diferenciada em função do indivíduo) e moderação contextual e cultural (processo de proteção avaliado e disponibilizado de acordo com o contexto e cultura). ${ }^{13} \mathrm{~A}$ distribuição dos níveis de resiliência entre cuidadores (familiares) de idosos dependentes e as características de cuidadores altamente resilientes foi estudada, destacando-se o elevado nível de resiliência como fator protetor. ${ }^{14}$

O cuidar no lugar vem ao encontro do desejo dos pacientes, em particular idosos, e suas famílias, podendo ser uma medida social e economicamente eficiente. Existindo estruturas de suporte ao cuidar no lugar, os cuidadores com potencial devem ser encorajados e as suas experiências estudadas. Deveria desenvolver-se uma linha de investigação translacional que incluísse as ciências da saúde e sociais e que permitisse mapear experiências positivas de cuidar e conhecer as características que lhes conferem sentido de coerência e resiliência.

\section{REFERÊNCIAS BIBLIOGRÁFICAS}

1. Van Durme T, Macq J, Jeanmart C, Gobert M. Tools for measuring the impact of informal caregiving of the elderly: a literature review. Int J Nurs Stud. 2012;49(4):490-504.

2. Gomes B, Sarmento VP, Ferreira PL, Higginson IJ. Estudo epidemiológico dos locais de morte em Portugal em 2010 e comparação com as 
preferências da população Portuguesa [Epidemiological study of place of death in Portugal in 2010 and comparison with the preferences of the Portuguese population]. Acta Med Port. 2013;26(4):327-34. Portuguese

3. Ishikawa Y, Fukui S, Saito T, Fujita J, Watanabe M, Yoshiuchi K. Family preference for place of death mediates the relationship between patient preference and actual place of death: a nationwide retrospective cross-sectional study. PLoS One. 2013;8(3):e56848.

4. Brick $Y$, Lowenstein A. Ageing in place [Internet]. Toronto: International Federation on Ageing; 2011. Available from: http://www.ifa-fiv.org/wpcontent/uploads/global-ageing/7.2/7.2.full.pdf

5. Mestheneos E. Ageing in place in the European Union. IFA Glob Ageing. 2011;7(2):17-24.

6. Bartlett $H$, Carroll M. Ageing in place down under. IFA Glob Ageing. 2011;7(2):25-34.

7. Bastawrous M. Caregiver burden: a critical discussion. Int J Nurs Stud. 2013;50(3):431-41.

8. Lee $\mathrm{H}$, Singh J. Appraisals, burnout and outcomes in informal caregiving. Asian Nurs Res (Korean Soc Nurs Sci). 2010;4(1):32-44.

9. Deeken JF, Taylor KL, Mangan P, Yabroff KR, Ingham JM. Care for the ca- regivers: a review of self-report instruments developed to measure the burden, needs, and quality of life of informal caregivers. J Pain Symptom Manage. 2003;26(4):922-53.

10. Decreto-Lei n 101/2006, de 6 de junho. Diário da República. $1^{\text {a }}$ série$A(109)$.

11. Matsushita M, Ishikawa T, Koyama A, Hasegawa N, Ichimi N, Yano H, et al. Is sense of coherence helpful in coping with caregiver burden for dementia? Psychogeriatrics. 2014;14(2):87-92.

12. Eriksson M, Lindström B. Validity of Antonovsky's sense of coherence scale: a systematic review. J Epidemiol Community Health. 2005;59(6):460-6.

13. Ungar $M$, Ghazinour $M$, Richter J. Annual research review: what is resilience within the social ecology of human development? J Child Psychol Psychiatry. 2013;54(4):348-66.

14. Crespo M, Fernández-Lansac V. Resiliencia en cuidadores familiares de personas mayores dependientes [Resilience in caregivers of elderly dependent relatives]. Anal Psicol. 2015;31(1):19-27. Spanish

\section{ENDEREÇO PARA CORRESPONDÊNCIA}

director@rpmgf.pt 